\title{
Costa RicA DESPUÉS DEL TLC: ¿LA CALMA QUE SIGUE
} A LA TEMPESTAD?

\section{Costa Rica after CAFTA: The Calm that Follows the Storm?}

\section{LUDOVICO FEOLI}

Tulane University

\begin{abstract}
RESUMEN
La resolución del conflicto político alrededor de la ratificación del Tratado de Libre Comercio con los Estados Unidos, Centroamérica, y la República Dominicana (DRCAFTA) representó una importante oportunidad política para Costa Rica en el 2008. No obstante, el gobierno no logró aprovechar la coyuntura para avanzar en problemas de fondo más allá de la Agenda de Implementación del Tratado. Su incapacidad de establecer un espacio de encuentro con la oposición, aunada a la debilidad de su mandato y a los obstáculos estructurales del sistema político, coartaron la posibilidad de construir consensos. En suma, la ausencia de una conducción estratégica hizo del año una oportunidad perdida para alcanzar logros políticos sustantivos.
\end{abstract}

Palabras clave: Crisis financiera y económica, partidos políticos, políticas públicas, coaliciones parlamentarias, poderes de Estado, Costa Rica.

\begin{abstract}
The end of the political conflict surrounding the ratification of the Dominican Republic and Central American Free Trade Agreement (DR-CAFTA) presented significant political opportunities for Costa Rica in 2008. But the government was unable to seize the initiative and establish a constructive political dialogue. Coupled with the structural limitations of the political system and its weak political mandate, this hindered its ability to advance in key areas beyond CAFTA. In all, the absence of a strategic vision made the year a lost opportunity for substantive political progress.
\end{abstract}

Key words: International financial and economic crisis, political parties, public policy, legislative coalitions, State powers, Costa Rica.

* El autor agradece a Jorge Vargas C. y Constantino Urcuyo F. por sus valiosos comentarios y a Natalia Morales y Victoria Salgado por la actualización de los indicadores de los Cuadros 1 y 2, respectivamente. 


\section{INTRODUCCIÓN}

Después del intenso movimiento ocasionado por el referéndum de ratificación del Tratado de Libre Comercio entre Estados Unidos, Centroamérica y la República Dominicana (CAFTA) en el 2007, el 2008 fue, en lo político, un año relativamente calmo. Dado que la principal actividad política consistió en la aprobación de las leyes complementarias del Tratado de Libre Comercio, dicho tema continuó dominando el escenario político nacional. Por una parte, ello permitió al gobierno mantener la coalición de 38 diputados que constituyó para la aprobación y posterior implementación del Tratado. ${ }^{1}$ Pero, por la otra, impidió el conocimiento de otros temas de importancia, creando la percepción de que el gobierno carecía de rumbo en un momento crítico del entorno internacional.

El gobierno también se vio afectado por revelaciones sobre sus prácticas que acusaron una relativa opacidad en la administración pública. Tal fue el caso del manejo dado por el gobierno a recursos obtenidos de fuentes externas, a los eventos relacionados con el restablecimiento de relaciones con la República Popular China en años previos y al control de la Dirección Interna de Seguridad. Antes que tender puentes de diálogo que acercaran al gobierno a la oposición, el Ministro de la Presidencia propuso resolver la ingobernabilidad por la vía de una asamblea constituyente. Tanto la propuesta como las bases en que se sustentaba fueron cuestionadas. ${ }^{2}$

El 2008 mostró la existencia de una fuerte oposición extraparlamentaria con una importante capacidad de resistencia al poder constituido. Su composición es diversa e incluye organizaciones de base como los Comités Patrióticos, organizaciones ambientalistas, sindicatos y sectores universitarios. Su accionar fue visible en la oposición a proyectos del Ejecutivo en materia de infraestructura y minería.

El período finalizó con el desfogue de los vientos electorales con miras a las elecciones presidenciales del 2010. Una polémica declaración del Presidente de la República se interpretó como un intento de designar a su vicepresidenta como su sucesora, abriendo paso a la manifestación de otras tendencias para la candidatura del Partido Liberación Nacional (PLN). El forcejeo preelectoral también se hizo evidente en el Partido Acción Ciudadana (PAC) en donde algunas personalidades declararon la necesidad de abrir la candidatura a un proceso de elección interna. También el Partido Unidad Social Cristiana (PUSC) movilizó sus fueros para alterar sus estatutos de forma que permitieran la postulación de su principal candidato.

El presente artículo analizará la situación política de Costa Rica en el 2008 a la luz de estos desarrollos. Su énfasis será sobre los hechos más notables del período, con especial atención a su relevancia política e informado por el desarrollo político-institucional reciente del país. 


\section{TEMAS SALIENTES DE LA REALIDAD NACIONAL EN EL 2008}

Durante el 2008 se revirtió la tendencia de crecimiento económico vigoroso que venía mostrando el país durante los tres años anteriores (Cuadro 1). Estimaciones preliminares muestran que el Producto Interno Bruto creció a menos de la mitad de su tasa de expansión en el 2007, pasando de un 7,8\% a un 2,9\%. Ello se debió al incremento de los precios internacionales de los alimentos y los combustibles en la primera mitad del año y a la desaceleración de la economía mundial y la recesión en los Estados Unidos en la segunda (CEPAL 2008). La repercusión sobre el PIB per cápita fue aún más notable, pues pasó de crecer un 6\% en el 2007 a crecer un 1,3\% en el 2008. A pesar de que estas

Cuadro 1: Costa Rica. Indicadores seleccionados de la evolución económica y social, 2002-2008

\begin{tabular}{|c|c|c|c|c|c|c|c|c|}
\hline Indicador & 2002 & 2003 & 2004 & 2005 & 2006 & 2007 & $\begin{array}{l}\text { Promedio } \\
\text { 2002-2007 }\end{array}$ & $2008^{\mathrm{a}}$ \\
\hline $\begin{array}{l}\text { PIB (millones } \\
\text { de dólares) }\end{array}$ & $16.844,4$ & $17.517,7$ & $18.595,6$ & $19.961,0$ & $22.528,7$ & $26.267,3$ & $20.285,8$ & $29.834,5$ \\
\hline $\begin{array}{l}\text { PIB per cápita } \\
\text { (dólares) }\end{array}$ & $4.118,8$ & $4.201,2$ & $4.377,0$ & $4.614,4$ & $5.118,0$ & $5.867,6$ & $4.716,2$ & $6.557,2$ \\
\hline Crecimiento del PIB real & 2,9 & 6,4 & 4,3 & 5,9 & 8,8 & 7,8 & 6,0 & 2,9 \\
\hline $\begin{array}{l}\text { Crecimiento del PIB } \\
\text { per cápita real }\end{array}$ & 0,86 & 4,36 & 2,33 & 3,99 & 6,90 & 5,99 & 4,1 & 1,28 \\
\hline $\begin{array}{l}\text { Exportaciones } \\
\text { (millones de dólares) }\end{array}$ & $5.263,5$ & $6.101,9$ & $6.301,5$ & $7.026,5$ & $8.199,8$ & $9.337,0$ & $7.038,4$ & $9.675,3$ \\
\hline $\begin{array}{l}\text { Crecimiento } \\
\text { exportaciones }\end{array}$ & 4,8 & 15,9 & 3,3 & 11,5 & 16,7 & 13,9 & 11,0 & 3,6 \\
\hline Déficit cuenta corriente & $-856,9$ & $-880,0$ & $-791,5$ & $-981,0$ & $-1.022,6$ & $-1.647,1$ & $-1.029,9$ & $-2.066,7$ \\
\hline $\begin{array}{l}\text { Déficit Cta. Cte. \% del } \\
\text { PIB }\end{array}$ & $-5,1$ & $-5,0$ & $-4,3$ & $-4,9$ & $-4,5$ & $-6,3$ & $-5,0$ & $-6,9$ \\
\hline $\begin{array}{l}\text { Inversión Extranjera } \\
\text { Directa }\end{array}$ & 659,4 & 575,1 & 793,8 & 861,0 & $1.469,1$ & $1.884,6$ & $1.040,5$ & $1.633,7^{\mathrm{b}}$ \\
\hline $\begin{array}{l}\text { Inversión Extranjera } \\
\text { Directa \% del PIB }\end{array}$ & 3,9 & 3,3 & 4,3 & 4,3 & 6,5 & 7,2 & 4,9 & 5,5 \\
\hline $\begin{array}{l}\text { Inflación } \\
(\% \text { cambio anual IPC })^{c}\end{array}$ & 9,7 & 9,9 & 13,1 & 14,1 & 9,4 & 10,8 & 11,2 & 13,9 \\
\hline $\begin{array}{l}\text { Tasa de desempleo } \\
\text { abierto }(\%)\end{array}$ & 6,4 & 6,7 & 6,5 & 6,6 & 6,0 & 4,6 & 6,1 & 4,9 \\
\hline $\begin{array}{l}\text { Tasa de subempleo } \\
\text { total (\%) }\end{array}$ & 14,6 & 15,0 & 14,4 & 15,0 & 15,0 & 12,0 & 14,3 & 11,7 \\
\hline $\begin{array}{l}\text { Inversión social real } \\
\text { (ISR) \% PIB }\end{array}$ & 19,7 & 19,4 & 18,6 & 18,1 & 17,6 & 18,1 & 18,6 & \\
\hline $\begin{array}{l}\text { ISR per cápita } \\
\text { (colones 2000) }\end{array}$ & 224,9 & 221,5 & 216,8 & 211,1 & 212,8 & 220,7 & 218,0 & \\
\hline $\begin{array}{l}\text { Hogares pobres } \\
\text { (porcentaje) }\end{array}$ & 20,6 & 18,5 & 21,7 & 21,2 & 20,2 & 16,7 & 19,8 & 17,7 \\
\hline Coeficiente de Gini & 0,432 & 0,427 & 0,420 & 0,408 & 0,422 & 0,429 & 0,423 & 0,428 \\
\hline
\end{tabular}

a Cifras preliminares.

b Cifra proyectada.

c Índice de Precios al Consumidor.

Fuente: Elaborado con datos del BCCR y del INEC. 
circunstancias no fueron únicas a Costa Rica, el país se situó por debajo de la media regional, ya que la economía latinoamericana creció a una tasa del 4,6\%, según datos de la CEPAL. Ello se debió a una disminución del consumo interno y a la contracción de las exportaciones, estimada en casi un 4\%. Aún así, el menor nivel de crecimiento no revirtió la tendencia inflacionaria observada en el 2007, ya que el índice de inflación llegó casi al $14 \%$, en buena parte a raíz del citado incremento en los precios internacionales. Esto aleja al país de su meta de reducir la inflación a un dígito, meta que apenas ha logrado aproximar en los últimos seis años.

En el campo social los resultados reflejaron el repliegue económico, aunque con intensidad moderada (Cuadro 1). Por una parte, el porcentaje de hogares pobres aumentó en un punto porcentual, situándose en $17,7 \%$ y perdiendo parte del terreno ganado durante el 2007, donde disminuyó en 3,5 puntos porcentuales. Aún así, dicho nivel es todavía significativamente inferior al del 2006 y, después del 2007, el más bajo desde que se registran los indicadores. Dicho aumento fue predominantemente en el nivel de pobreza no extrema y en zonas urbanas. El desempleo abierto aumentó pero de forma marginal, pasando de un $4,6 \%$ a un $4,9 \%$, mientras que la tasa de subempleo disminuyó de un $7,4 \%$ a un $6,8 \%$. En alguna medida estos indicadores reflejan el impacto positivo de un aumento del gasto público en infraestructura y en el sector social. La inversión social real aumentó en medio punto porcentual con respecto al PIB y casi un cuatro por ciento en su nivel per cápita. Si bien el gasto social en Costa Rica tiene un fuerte efecto redistributivo (Programa Estado de la Nación 2008) este importante esfuerzo es todavía insuficiente para compensar la brecha en los ingresos laborales. Medida por el coeficiente de Gini en el 2008 la desigualdad global se mostró por encima del promedio de los últimos seis años.

En síntesis, al igual que para el resto de la región latinoamericana, el 2008 marcó el final de un período de robusto crecimiento económico para Costa Rica. Como lo resalta la CEPAL, ese sexenio produjo una marcada mejoría en los indicadores del mercado de trabajo y de pobreza sin que se perdiera la estabilidad de los balances macroeconómicos. Cabe acotar que el gobierno alcanzó un superávit fiscal equivalente al 0,2\% del PIB en el 2008 (no mostrado en el Cuadro). Pero las circunstancias externas favorables que hicieron esto posible se revirtieron y los resultados económicos de Costa Rica, como los de la región, lo reflejan. ${ }^{3}$ Estas circunstancias, junto con los aspectos políticos que se comentarán, han calado en la opinión pública y su valoración de la gestión del gobierno. Las principales encuestas de opinión publicadas en el último trimestre del 2008 reflejaron un considerable deterioro de la opinión pública sobre la gestión de la administración Arias. ${ }^{4}$ Asimismo, el costo de la vida y el pesimismo respecto a la situación económica aparecieron como las principales preocupaciones de los hogares.

Y según los pronósticos más optimistas, lo seguirán reflejando por lo menos durante el 2009.

Véase, por ejemplo, "Cae apoyo ciudadano a la gestión del Presidente Arias" La Nación, 16 de septiembre, 2008; "Baja el apoyo a la Administración", La República, 5 de noviembre, 2008. Encuestas más recientes indican cierto repunte del apoyo a Arias en el 2009. 
No obstante, esto no pareció afectar la capacidad gubernamental para mantener unida la heterogénea coalición parlamentaria de 38 diputados y cinco partidos formada para impulsar la ratificación del CAFTA. Ello permitió que se aprobara una serie de leyes de trascendencia para el país, incluyendo la apertura a la competencia en los mercados de seguros y telecomunicaciones, que habían esperado en comisión por años. Cabe recalcar, sin embargo, que buena parte de estos proyectos formaron lo que se consideró la agenda de implementación del TLC ya que, por representar parte de los acuerdos negociados en el Tratado, la entrada en vigencia del mismo dependía de su aprobación. De ahí que los incentivos para la aprobación de estas leyes provinieron de la perentoriedad de la entrada en vigencia del Tratado más que de cualquier factor político. En efecto, la necesidad de lograr la aprobación de las citadas leyes complementarias mantuvo constreñida la capacidad del gobierno para impulsar una agenda legislativa más amplia.

De ahí que la coyuntura política del país en el 2008 se viera marcada por la continuidad en cuanto a la incapacidad del Ejecutivo para desarrollar una relación política constructiva y fluida con la oposición, particularmente con su principal bloque en el Congreso. Ausente esta relación, el Ejecutivo optó por idear mecanismos alternativos para agilizar su gestión cuyo efecto fue generar desconfianza y falta de credibilidad. Ejemplo de ello fue el manejo dado por el gobierno a fondos donados por la República de Taiwán, aparentemente estructurado para evitar los controles establecidos para el manejo de recursos públicos. Igualmente ocurrió con los acuerdos económicos ligados a las negociaciones para el establecimiento de relaciones diplomáticas con la República Popular China, manejadas en un cuestionable secreto. En un país sensibilizado ante la corrupción pública por el enjuiciamiento de dos ex presidentes, esto ocasionó un grave daño político al gobierno.

En la coyuntura internacional el gobierno dio seguimiento a la importante transformación de la política exterior que introdujo al inaugurar su mandato. Los ejes fundamentales de ese cambio fueron el restablecimiento de relaciones diplomáticas con China y el traslado de la embajada ante Israel de Jerusalén a Tel Aviv, seguido de un acercamiento político al mundo árabe e islámico. También incluyó la promoción de importantes iniciativas diplomáticas como el Consenso de Costa Rica, una propuesta para que los países desarrollados orienten sus donaciones de acuerdo a criterios éticos, y el Tratado Internacional para Regular el Comercio de Armas. Otro elemento importante de esta revigorización de la política externa fue la elección de Costa Rica, por tercera vez en su historia, como miembro no permanente del Concejo de Seguridad de las Naciones Unidas. En lo político, estas acciones fortalecieron la posición del gobierno, robusteciendo su reputación a nivel internacional. El gobierno también continuó impulsando la inserción del país en el comercio mundial mediante las negociaciones de un convenio de asociación con la Unión Europea y Centroamérica y la apertura de negociaciones para un tratado de libre comercio con China. 


\section{CAMBIOS INSTITUCIONALES, CONSTITUCIONALES Y EN POLÍTICAS PÚBLICAS}

Al igual que en el 2007, en el 2008 no se registraron reformas constitucionales ni realineamientos del entramado institucional del Estado costarricense. No obstante, el Parlamento aprobó un conjunto de leyes importantes derivadas de la agenda de implementación del CAFTA que afectará significativamente el entorno de mercado en el mediano plazo, como es el caso del rompimiento de los monopolios estatales en seguros y telecomunicaciones. En materia de políticas públicas el período se caracterizó por el marcado deterioro del entorno económico internacional que dificultó el alcance de las metas del Plan Nacional de Desarrollo. Pese a la gravedad de la crisis en ciernes, reconocida en ominosas declaraciones del propio Presidente de la República, ${ }^{5}$ el gobierno se limitó a aceptar la necesidad de replantear sus metas y esperó hasta el 2009 para presentar un plan específicamente diseñado para enfrentar las posibles consecuencias de la crisis. ${ }^{6}$ Ello puso en evidencia un vacío de liderazgo cuando el país requería actuaciones decisivas.

La ratificación vía referéndum del TLC consolidó la opción por un modelo económico abierto, hacia la inserción internacional en lo externo y hacia mercados competitivos en lo interno (Comisión de Notables 2005). Desde los años 80 Costa Rica avanzó significativamente en la apertura de su economía al comercio internacional mediante una agresiva desgravación arancelaria (Lora, 2007). Sin embargo, dicha liberalización no fue concurrente con la de otros importantes sectores, como las telecomunicaciones y los seguros, en los que se mantuvo una clara predominancia del sector público (Chong y Benavides, 2007). La agenda de implementación del tratado obligó al país a permitir la competencia en el campo de los seguros comerciales, la telefonía y el suministro de servicios de Internet llevando, de hecho, al rompimiento del monopolio público que existía en esos campos. No obstante, ello no implicó la privatización de esos sectores, dado que el Estado podrá seguir participando en ellos y beneficiarse de la importante ventaja de mercado que mantiene. ${ }^{7}$ En efecto, la agenda complementaria incluyó una ley para la modernización y el fortalecimiento del sector de telecomunicaciones que pretende mejorar las condiciones estructurales para la competitividad de las empresas estatales en ese campo.

El Plan Nacional de Desarrollo "Jorge Manuel Dengo", presentado por el gobierno en su primer año de gestión, propuso mejorar la eficacia y eficiencia de las políticas públicas mediante la asignación de metas nacionales y sectoriales y la coordinación de actividades entre las diferentes instituciones del sector público (Ministerio de Planificación y Política Económica 2007b). Dichos objetivos partieron de una reestructuración previa del Poder Ejecutivo en doce sectores funcionales en los que se agruparon las diversas instituciones del sector público y cuyas rectorías se asignaron a los diversos Ministros de Estado, con el apoyo de Consejos Sectoriales. La valoración de resultados de este esfuerzo durante el

5 Desde abril del 2008 en que expresó "mucho miedo" por lo que pudiera pasar con la pobreza, hasta posteriores advertencias sobre la venida de tiempos de "vacas flacas" y aumentos en el desempleo.

El "Plan Escudo", descrito al final de esta sección, fue presentado el 29 de enero del 2009.

Hasta la fecha de entrada en vigencia de la nueva legislación de monopolio legal. 
2008 arroja resultados mixtos. Por una parte, la Contraloría General de la República señaló el incumplimiento de metas en las áreas de salud y educación y criticó la inexistencia de plazos concretos para medir el avance de resultados (Contraloría General de la República 2008a, 2008b). Por otra parte, la autoevaluación efectuada por el MIDEPLAN (Ministerio de Planificación y Política Económica 2009) presenta una valoración más matizada. De las ocho grandes metas nacionales detalladas en el Plan se disciernen tres categorías generales: aquellas en las que se avanzó con claridad, aquellas en las que no se avanzó del todo o incluso se retrocedió y aquellas cuyo avance se mantiene indeterminado.

Las áreas en que el gobierno logró avanzar con respecto a sus metas, según el informe, son la recuperación de la infraestructura y el desarrollo de un papel protagónico en política exterior. La inversión en infraestructura creció en casi un 70\% durante el 2008 con respecto al 2007 y un $71 \%$ de esos recursos se destinaron a la red vial. También se logró una mejoría en el tonelaje movilizado en Puerto Caldera (Pacífico), aunque no así en Puerto Limón (Atlántico) y se hizo un esfuerzo importante por ampliar el servicio de ferrocarril, principalmente del tren urbano. En política exterior se consideraron superadas las expectativas del Plan por la identificación y apoyo brindados por la comunidad internacional a las iniciativas promovidas por Costa Rica, entre ellas, el Consenso de Costa Rica, Paz con la Naturaleza y la modificación del Tratado Internacional para la Producción, Comercialización y Exportación de armas. Cabe notar, además, el reconocimiento del Estado Palestino y el establecimiento de relaciones con éste.

Las áreas en que el gobierno no logró avanzar con respecto a sus metas incluyen el combate de la corrupción, la reducción de la pobreza y el crecimiento de la producción y el empleo. Sobre estas metas pesó el deterioro del entorno económico internacional que se manifestó en una reducción de la demanda por los bienes y servicios de exportación costarricenses, el aumento de la turbulencia financiera internacional que limitó el acceso al financiamiento externo y el aumento de los precios internacionales de granos y combustibles que elevó la línea de la pobreza. Ello llevó a que los puestos de trabajo creados fueran insuficientes, elevando el desempleo, y a que los niveles de pobreza aumentaran con respecto al 2007. Durante el 2008 el gobierno reconoció la necesidad de replantear las metas del Plan de Desarrollo a la luz de estas condiciones, que no se anticiparon en la formulación del Plan. Aun así, cabe resaltar que el gobierno no logró impulsar la ley que crearía el Ministerio de Desarrollo Social y Asentamientos, pieza clave de su propuesta para la vigorización de las políticas sociales. En cuanto a la corrupción, el índice de control de corrupción empleado por el gobierno para aproximarse al cumplimiento de la meta nacional no registró mejoría sino más bien un leve deterioro.

Finalmente, las áreas cuyo avance se mantiene indeterminado son las relativas a mejorar la calidad y cobertura de la educación, detener el crecimiento de la criminalidad y la percepción de inseguridad entre la ciudadanía y fortalecer las instituciones públicas y ordenar las prioridades del Estado. En materia de educación la inversión de un 5,17\% del PIB distó en mucho de la meta del 8\% fijada por el gobierno en su Plan Nacional de Desarrollo (Ministerio de Planificación y Política Económica 2007b). ${ }^{8}$ Si bien el informe 
dio cuenta de una serie de decisiones del Ministerio de Educación para reducir la repitencia y deserción, mejorar la educación técnica y mejorar la capacitación de docentes $\mathrm{y}$ funcionarios, sus efectos son desconocidos a la fecha.

En cuanto a detener el crecimiento de la criminalidad y revertir la sensación de inseguridad de la ciudadanía el informe resume un conjunto de acciones cualitativas y cuantitativas, incluyendo la promoción de proyectos de ley, aumentos de personal y desarrollo de sistemas de información, entre otros, pero sin poder determinar todavía su impacto sobre la meta deseada. Por el contrario, los datos sobre victimización publicados al final del período por el Instituto Nacional de Estadística y Censos con base en la Encuesta de Hogares revelaron una preocupante tendencia: en los últimos diez años el porcentaje de hogares víctimas de al menos un delito casi se duplicó, pasando del 15\% al 28\% entre 1997 y 2008 (INEC y PNUD 2008). Dicho ascenso se acompañó de una disminución del porcentaje de hechos denunciados durante el mismo período.

En lo tocante al fortalecimiento y ordenamiento de las instituciones estatales el informe resalta los reglamentos decretados (en el 2008) para la organización del Poder Ejecutivo y las 87 propuestas emanadas de la Comisión de Eficiencia Administrativa y Reforma del Estado. No obstante, no es posible trazar sus efectos a resultados concretos.

El gobierno fue criticado por no articular una rápida y decidida respuesta de política pública a la crisis financiera y económica internacional que se perfiló a lo largo del segundo semestre del año. A pesar de los claros signos de deterioro en la producción y el empleo, muchos de ellos comentados públicamente por el propio Presidente de la República, el gobierno esperó hasta enero del 2009 para presentar un plan comprensivo contra los efectos de la crisis. Ello se interpretó como una patente subestimación de la magnitud de la crisis por parte del gobierno o bien como su incapacidad de responder ante la misma. El denominado Plan Escudo propuso dar asistencia a las familias de clase media y de menores recursos, combatir el desempleo y mejorar las condiciones de negocios para las empresas a través del gasto social, el incremento de la obra pública, la facilitación y el abaratamiento del crédito y la reducción de costos implícitos en regulaciones fiscales y de otra índole. Pero el Plan careció de medidas específicas para el fomento de la producción y el empleo. Con respecto a este último punto, se propuso la flexibilización laboral como mecanismo de preservación del empleo, medida polémica que algunos sectores sociales cuestionaron por considerar que tendría un impacto negativo sobre los salarios. Además de la insuficiencia del Plan ante la magnitud de la crisis se cuestionó su capacidad de entrar en vigencia con la rapidez suficiente, dada su dependencia sobre medidas sujetas a la aprobación de la Asamblea legislativa.

\section{RESULTADOS DE ELECCIONES NACIONALES Y SUBNACIONALES}

Durante el 2008 no se celebró ninguna elección nacional o subnacional en Costa Rica. Esto representó un cambio importante en la actividad electoral con respecto a los dos años anteriores, ya que en el 2006 se celebró la elección presidencial, legislativa y municipal y en el 2007 se llevó a cabo el referéndum nacional para la ratificación del CAFTA. No obstante, en el 2008 inició la actividad política con miras a las elecciones presidenciales 
del 2010. Esto es notable por tres motivos. Primero, porque se desencadenó al manifestar públicamente el Presidente de la República su deseo de ser sucedido por una mujer en la presidencia. Esto se interpretó como un intento del mandatario por ungir a su vicepresidenta como la candidata designada de su partido. Segundo, porque ello obligó a otras corrientes políticas a manifestarse, forzando una prematura apertura de la contienda primaria presidencial. Tercero, porque esto eventualmente obligó a la vicepresidenta a renunciar a su cargo para dedicarse a la actividad proselitista, creando un vacío en un puesto de elección popular sin mecanismos preestablecidos para su reemplazo (ver sección sobre Poder Legislativo).

En este contexto, y en la perspectiva de las elecciones presidenciales del 2010, el apoyo partidario se mostró bastante indefinido al concluir el año 2008. En las principales encuestas de opinión publicadas durante el último trimestre el mayor bloque de votantes, un $44 \%$, manifestó no tener preferencia por partido alguno, y ninguno de los partidos existentes contó con el apoyo suficiente para ganar la elección en primera ronda con una pluralidad de los votos (UNIMER 2008; CID-Gallup 2008). ${ }^{9}$ Esto parece reflejar la tendencia de desalineación entre partidos y votantes que ha venido manifestándose en el país en años recientes (Achard y González 2005; Boidi 2008). La principal fuerza electoral entre los que manifestaron preferencias la conforma el partido oficialista, Liberación Nacional (PLN), seguido del Partido Unidad Social Cristiana (PUSC), ambos partidos de mayor tradición que dominaron la escena política durante el período del bipartidismo (1986-2002). Les sigue el Partido Acción Ciudadana (PAC). ${ }^{10}$

A más de dos años de las elecciones presidenciales estos datos son muy preliminares. Debe considerarse, como ya se dijo, que un alto porcentaje del electorado aún no manifiesta su preferencia partidaria. Por otro lado, la filiación partidaria no ha sido un buen indicador del resultado electoral final en contiendas presidenciales recientes. En el 2004, a dos años de la elección presidencial, la preferencia partidaria expresada a favor del candidato del PAC rondó el 17\% (UNIMER 2004), pero en la elección del 2006 dicho candidato obtuvo un $39,8 \%$ de los votos, monto cercano al del ganador. Asimismo, el PAC salió de la elección como el segundo partido políticamente más importante (ver sección Poder Legislativo). La interrogante que surge hacia el 2010 es si el PAC podrá explotar su posición actual como principal partido opositor para elevar su apoyo por encima de los niveles logrados en el 2006. Por su parte, el PUSC muestra una persistente lealtad partidaria a pesar de su vinculación a procesos de corrupción revelados en el 2004, probablemente a raíz de la lealtad del Calderonismo histórico. ${ }^{11}$ A pesar de no ser por sí solo suficiente para alcanzar un triunfo presidencial, si persistiera dicho apoyo podría dar al partido un importante peso político en una segunda ronda electoral. ${ }^{12}$

$9 \quad$ Establecida constitucionalmente en un $40 \%$ (art. 138).

10 Las encuestas de Unimer (2008) y CID-Gallup (2008) reflejaron las preferencias partidarias como sigue: PLN entre un $25 \%$ y un $33 \%$; PUSC un $16 \%$; PAC entre un $7 \%$ y un $12 \%$.

11 Al igual que el Liberacionismo, el Calderonismo tiene sus orígenes históricos en la llamada Revolución de 1948 en donde las principales tendencias políticas se alinearon alrededor del liderazgo de José Figueres Ferrer y Rafael Ángel Calderón Guardia, respectivamente.

12 Las principales encuestas hablan de un apoyo partidario cercano al 15\% para el PUSC. 
Tanto el PLN como el PAC enfrentarán un proceso de elecciones primarias en el 2009 para elegir su candidato presidencial. Los principales contendientes dentro de Liberación Nacional son la exvicepresidenta Laura Chinchilla y el exalcalde de San José, Johnny Araya Monge. En cuanto al Partido Acción Ciudadana, su fundador y dos veces candidato a la presidencia de la República, Otón Solís, se enfrentará por primera vez a un proceso de convención interna para definir al postulante presidencial del 2010. Su principal contendiente es la ex presidenta del partido y ex candidata a la vicepresidencia de la República en el 2006, Epsy Campbell.

\section{PODER EJECUTIVO}

Durante el 2008 el Poder Ejecutivo se vio sacudido por escándalos de opinión pública que llevaron a la dimisión de dos ministros de Estado. Asimismo, la vicepresidenta de la República (ver sección anterior) representó una tercera baja del gabinete ministerial, ya que se desempeñaba como Ministra de Justicia, elevando a seis el total de renuncias en los dos primeros años de la administración Arias (Cuadro 2). El deterioro de la imagen del Ejecutivo durante el período propició la creación de un nuevo puesto de rango ministerial para mejorar el manejo de la comunicación y la imagen del gobierno, el Ministerio de Comunicación e Información.

Dicha imagen se vio lesionada por la percepción de que el gobierno faltó a los principios de publicidad y transparencia en una serie de hechos revelados a lo largo del 2008. El primero de esos hechos se suscitó cuando el entonces Ministro de Seguridad Pública denunció la existencia de vínculos de las Fuerzas Armadas Revolucionarias de Colombia (FARC) con políticos nacionales pero desistió de comparecer ante el Poder Legislativo para explicarlos hasta después de dejar, repentinamente, el cargo. Los presuntos vínculos y las condiciones de su separación del cargo nunca fueron aclarados. ${ }^{13}$ Posteriormente trascendió que una donación del Banco Centroamericano de Integración Económica (BCIE) procuró manejarse en fideicomisos estructurados aparentemente para eludir los controles establecidos para las contrataciones del Estado. ${ }^{14}$ Poco tiempo después se supo que una donación del gobierno de Taiwán para el mejoramiento de la calidad de vida de 600 familias pobres se había destinado, a través de mecanismos igualmente cuestionables, al pago de consultorías. Esto provocó la renuncia del Ministro de Vivienda, quien también fungía como rector del sector social. ${ }^{15}$ Finalmente, se conoció que el gobierno incluyó, de forma secreta, la venta de bonos de deuda pública en sus negociaciones para el establecimiento de relaciones diplomáticas con la República Popular China. Los términos de la transacción trascendieron hasta meses después de

13 "Dinero de las FARC y nexos de políticos avivaron polémica". La Nación, 1 de abril, 2008; "Berrocal deja Seguridad Pública". La República, 31 de marzo, 2008.

14 “Rodrigo Arias: Gobierno usó BCIE para ganar agilidad”. La Nación, 6 de julio, 2008; “Donaciones al gobierno operan sin controles". La Nación, 1 de julio, 2008; “Diputados exigen destape de fondo manejado en secreto". La Nación, 1 de julio, 2008.

15 "Zumbado pidió a Taiwán transferir donación al BCIE". La Nación, 18 de julio, 2008; "Zumbado renuncia al Ministerio de Vivienda". La Nación, 6 de agosto, 2008. 
su formalización, y sus detalles fueron divulgados reticentemente y sólo ante la orden de la Sala Constitucional. ${ }^{16}$

La reacción del Ejecutivo ante estos hechos fue de indignación, acusando a los medios de comunicación de persecución y acoso. El Presidente de la República se declaró "cansado" de las críticas y pidió que "lo dejaran gobernar" ${ }^{17}$ El ministro de la Presidencia declaró la existencia de una crisis de gobernabilidad, expresada en la incapacidad del Estado para tomar decisiones y resolver problemas con prontitud y oportunidad, y abogó por la necesidad de convocar a una asamblea constituyente para modificar a fondo la ley fundamental de la República. En medio de estas tensiones se conoció que la Dirigencia de Inteligencia y Seguridad Nacional, entidad adscrita a la Presidencia de la República y encargada de labores de inteligencia interna, operaba sin controles externos, lo que le permitía cometer toda suerte de abusos, incluyendo la utilización de recursos de inteligencia para cometer presuntos fraudes o ponerse al servicio de narcotraficantes. Esta situación, contrapuesta a los principios democráticos de legalidad, transparencia y responsabilidad contribuyó a erosionar la imagen pública del Ejecutivo.

Al mismo tiempo, se produjo una activa movilización de organizaciones de la sociedad civil en contra de proyectos favorecidos por el Ejecutivo. Algunas de estas acciones constituyeron, en efecto, una importante oposición extraparlamentaria al gobierno, tal como lo ilustran los casos concretos de la minería en Crucitas de San Carlos y del acueducto de Sardinal. Ambos casos se valieron de la movilización social mediante protestas y denuncias para detener acciones del Estado consideradas perjudiciales por miembros de las respectivas comunidades. También en ambos casos los movimientos consistieron de grupos heterogéneos que compaginaron la acción de organizaciones de base comunal con organizaciones nacionales y en algunos casos partidos políticos, explotando, mediante un creativo repertorio de métodos contenciosos (Tarrow 1994), las tensiones y contradicciones inherentes en las políticas a las que se oponían. Finalmente, en ambos casos los movimientos complementaron su acción de protesta con el uso de las instituciones de control horizontal y de rendición de cuentas existentes en el ordenamiento jurídico nacional.

En el caso de las Crucitas, organizaciones ambientalistas lideraron la oposición a un decreto ejecutivo que eliminó la moratoria existente contra la minería de cielo abierto, abriendo el paso a una explotación de oro por parte de una empresa canadiense en la zona norte del país. En su campaña, dichas organizaciones reclutaron el apoyo de organizaciones comunales para protestar públicamente contra la decisión, alegando su vasto potencial de daño ambiental. A dichas protestas se unieron partidos de oposición (Acción Ciudadana y Frente Amplio) y organizaciones sindicales (ANEP, UPINS). El repertorio de tácticas empleadas por el movimiento partió del señalamiento de una contradicción inherente en la decisión del Ejecutivo. Por una parte, el gobierno basaba su política exterior en la promoción de paz con la naturaleza. Por la otra, declaraba de

16 “Gobierno mintió al país sobre venta de bonos a China". La Nación, 11 de septiembre, 2008; “Sala IV exige al Gobierno dar información de bonos chinos". La Nación, 6 de septiembre, 2008.

17 "Un Arias "cansado" de críticas pide que lo dejen gobernar". La Nación, 16 de septiembre, 2008. 
interés público una explotación minera cuyo riesgo ecológico era ostensiblemente alto. Dicha contradicción sirvió de base para que el movimiento cursara una demanda contra el Presidente de la República y el ministro del Ambiente, ambos firmantes del decreto, por el delito de prevaricato. ${ }^{18}$ El Ministerio Público ordenó una investigación al efecto. La polémica ocasionada consiguió incluso que la Fundación Paz con la Naturaleza, organización creada por el propio Presidente Arias para promover políticas acordes con la naturaleza, recomendara al Ejecutivo declarar una nueva moratoria sobre la minería a cielo abierto. El movimiento eventualmente logró frenar temporalmente el proyecto mediante un recurso de amparo admitido por la Sala Constitucional.

En el caso del acueducto de Sardinal, organizaciones comunales reaccionaron ante un convenio entre el sector público y el sector privado para la ampliación de un acueducto en la zona de Guanacaste. Sardinal es una comunidad relativamente pobre y predominantemente rural de unos ocho mil habitantes, situada en un polo de alto desarrollo turístico e inmobiliario (Ramírez H. 2008). Por encontrarse en ella la cuenca del Río Sardinal, goza de fuentes de agua en una zona en donde el agua tiende a ser relativamente escasa. De ahí que el acuífero de esta cuenca es indispensable para el suministro de las comunidades y los sitios costeros aledaños. El acueducto en cuestión beneficiaría a los desarrollos turísticos de la zona y activó el temor de la comunidad local en cuanto a la disposición y la suficiencia del recurso hídrico. Las tácticas contenciosas empleadas por el movimiento giraron en torno a estos aspectos, puntualizando que, pese a ser un recurso local su explotación no beneficiaba a la comunidad, y recordando las divisiones suscitadas respecto a la privatización del agua en la recién concluida campaña de ratificación del TLC (Programa Estado de la Nación 2008). En efecto, a las protestas en contra del acueducto se sumaron grupos nacionales que en su momento formaron parte de la coalición opositora al Tratado, como los Comités Patrióticos y algunos grupos sindicales. El movimiento, además de las tácticas de presión, empleó los mecanismos de control horizontal para promover su causa, recurriendo a la Defensoría de los Habitantes y a la Procuraduría de la República. Las presiones llevaron a la Municipalidad competente a suspender las obras y a que el gobierno formara una comisión interinstitucional y de expertos que tomara en cuenta las inquietudes de la comunidad.

Durante el 2008 la composición del gabinete ministerial se mostró mucho más inestable que durante el período anterior. Además de los cambios ya comentados a nivel de ministros, diez viceministritos salieron de sus puestos, la tercera parte del gabinete (Cuadro 2). Una proporción similar de las presidencias ejecutivas de entidades autónomas sufrió cambios durante el período.

\section{PODER LEGISLATIVO}

La dinámica legislativa durante el 2008 estuvo dominada por la aprobación de un conjunto de leyes que formaban parte de los compromisos adquiridos por el país tras 


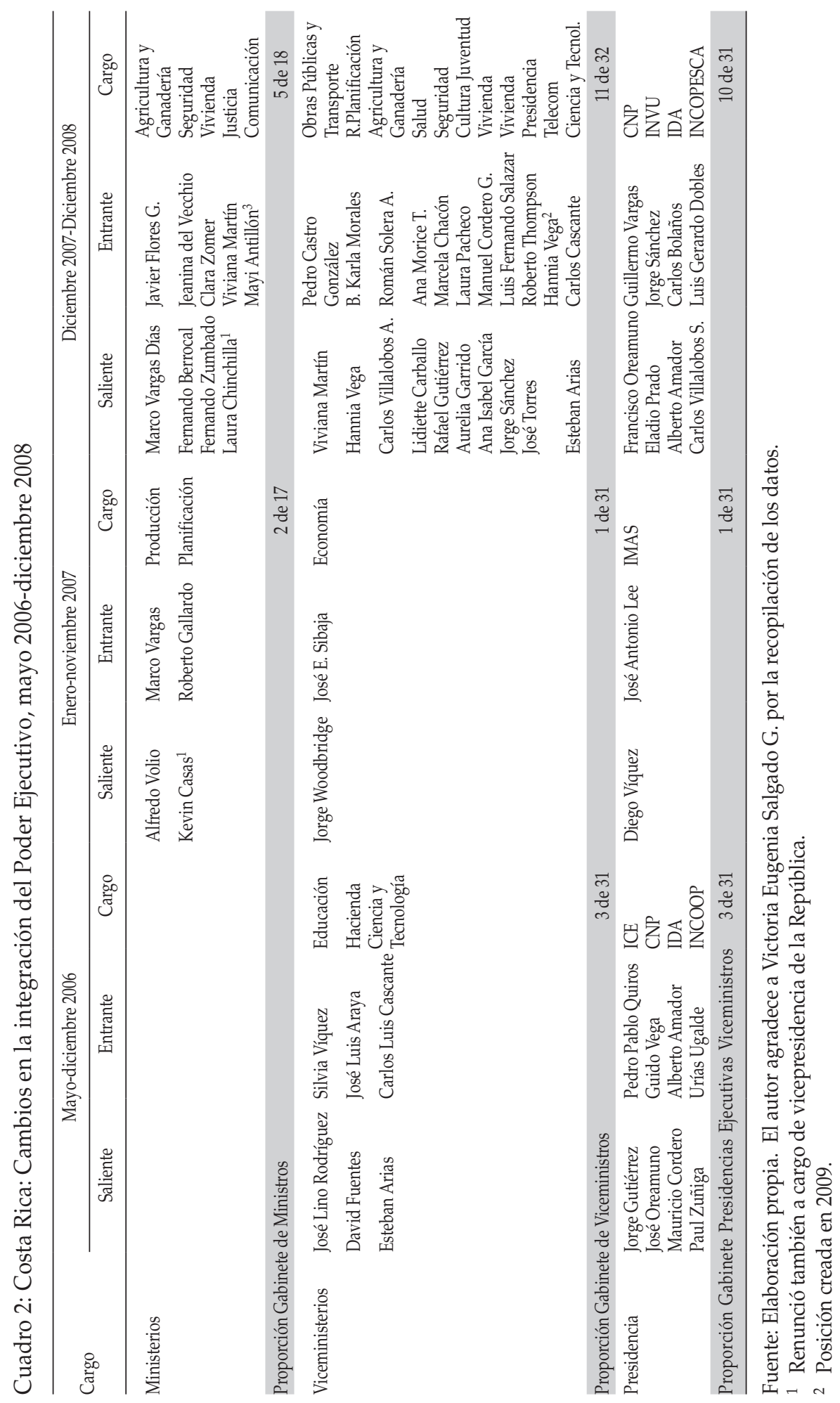


la ratificación del Tratado de Libre Comercio con Centroamérica, Estados Unidos y República Dominicana. La perentoriedad de la fecha límite para la entrada en vigencia del tratado sirvió para impulsar estas leyes, lo que a su vez requirió mantener la cohesión de la coalición mayoritaria formada para promover la aprobación del tratado. Dicha coalición de cinco partidos de centro-derecha representa una holgada mayoría, 38 de 57 escaños (Vargas Cullel 2008). Más allá del Tratado la Asamblea mejoró su nivel de productividad con respecto a los dos años previos en campos como la seguridad vial, el fomento de vivienda, el financiamiento del desarrollo y la concesión de obra pública. Pero otros proyectos importantes de interés para el gobierno no lograron avanzar.

En el período de enero a diciembre de 2008 la Asamblea Legislativa aprobó 78 leyes, de las cuales 11 correspondieron a la agenda de implementación del CAFTA. De ahí que la labor legislativa que no estuvo vinculada a la ratificación del CAFTA produjo un conjunto de 67 leyes. Un 34\% de esas leyes consistió de asuntos de orden procedimental, como las autorizaciones estatutarias a entidades públicas para segregar bienes inmuebles o a gobiernos locales para el cobro de impuestos; o simbólico, como los reconocimientos honoríficos a personas o instituciones o las declaratorias de días festivos. La categoría de legislación ordinaria destinada a la creación o reforma de entidades públicas y aprobación de presupuestos del gobierno central representó casi un 50\% de la actividad legislativa fuera del TLC.

Cuadro 3: Costa Rica, leyes aprobadas, enero-diciembre 2008

\begin{tabular}{lrrrr}
\hline Tipo de Leyes & \multicolumn{2}{c}{ Leyes Aprobadas } & \multicolumn{2}{c}{ Excluyendo AC } \\
\hline Agenda Complementaria TLC (AC) & 11 & $14 \%$ & & \\
Autorizaciones locales & 20 & $26 \%$ & 20 & $30 \%$ \\
Convenios internacionales & 11 & $14 \%$ & 11 & $16 \%$ \\
Declaraciones y Benemeritazgos & 3 & $4 \%$ & 34 & $\%$ \\
Legislación ordinaria sustantiva & 28 & $36 \%$ & 28 & $42 \%$ \\
Presupuesto & 5 & $6 \%$ & 5 & $7 \%$ \\
Total & 78 & $100 \%$ & 67 & $100 \%$ \\
\hline
\end{tabular}

Fuente: Elaboración propia con datos de la Asamblea Legislativa.

Dicha actividad legislativa deparó al gobierno algunos logros en objetivos específicos de su gestión. Cabe resaltar la aprobación de un impuesto específico para el fortalecimiento de programas de vivienda y de una ley para la titulación de viviendas en zonas urbanas no reconocidas, ambas coadyuvantes a la meta de erradicación de tugurios fijada por el gobierno. También debe resaltarse la aprobación de una amplia modificación de la Ley de Tránsito que eleva el poder disuasivo de la legislación mediante la creación de multas y la penalización de algunas infracciones. Dicha legislación representa una decisiva respuesta de política pública ante la alarmante incidencia de fatalidades viales existente en el país, siendo la primera categoría de muertes por causa violenta (Ministerio de Planificación y Política Económica 2009). También se logró la aprobación de un proyecto de Banca de Desarrollo que busca canalizar recursos financieros provenientes de varias fuentes, 
incluidos los aportes pagados por intermediarios financieros del sector privado para su incorporación al negocio de cuentas corrientes, a sectores productivos en condiciones blandas. Finalmente, la aprobación de una reforma que mejora el régimen de concesión de obra pública permitiría el desarrollo de importantes obras de infraestructura pendientes por muchos años.

No obstante estos logros puntuales, otro conjunto de proyectos de importancia para el gobierno no avanzaron en su aprobación. Entre ellos se destacan la creación del Ministerio de Desarrollo Social y Asentamientos, la reforma para elevar el financiamiento de la educación pública, la reforma electoral, la reforma tributaria y las reformas para mejorar la seguridad ciudadana.

La dificultad con que avanza el trabajo legislativo quedó en evidencia en el análisis de los días requeridos para el trámite de las leyes (Cuadro 4). Las leyes aprobadas durante el 2008 requirieron entre 18 días y 76 meses para tramitarse, lo que incorpora un rango bastante amplio de variabilidad (véase el apéndice para mayor detalle). No obstante, la distribución de frecuencias para los días de tramitación muestra que sólo un $22 \%$ de las leyes se tramitaron en un año y que el $46 \%$ de éstas requirieron más de los dos años para llegar a ser ley. El promedio de duración general para las leyes aprobadas en el período fue de 25 meses. ${ }^{19} \mathrm{Si}$ se toma en consideración que esto equivale a más de la mitad del periodo constitucional del Ejecutivo resulta evidente que la capacidad de acción del gobierno es restringida. La lentitud con que avanzan las leyes privilegia los cambios parciales por encima de las reformas integrales, lo cual no pocas veces redunda en demérito de su calidad (Chinchilla 2009). ${ }^{20}$

Cuadro 4: Costa Rica, Distribución de Frecuencias de la Duración en Aprobación de Leyes

\begin{tabular}{cccc}
\hline Días & Meses & Frecuencia & $\%$ \\
\hline 30 & 1 & 3 & $4,1 \%$ \\
90 & 3 & 3 & $4,1 \%$ \\
120 & 4 & 1 & $1,4 \%$ \\
180 & 6 & 3 & $4,1 \%$ \\
360 & 12 & 6 & $8,1 \%$ \\
540 & 18 & 13 & $17,6 \%$ \\
720 & 24 & 11 & $14,9 \%$ \\
$>720$ & $>24$ & 34 & $45,9 \%$ \\
\hline
\end{tabular}

Fuente: Elaboración propia con datos de Asamblea Legislativa.

19 Los datos corresponden al período de análisis de este anuario, que es al año calendario (enero-diciembre). El año legislativo en Costa Rica va del 1 de mayo al 30 de abril. Esta diferencia dificulta la comparación con datos publicados sobre la duración del trámite legislativo en períodos anteriores, que corresponden al año legislativo. No obstante, los días de trámite promedio en el año calendario 2008 representaron un aumento con respecto al promedio de los últimos cuatro períodos legislativos (véase el Apéndice).

20 Las implicaciones en el ámbito penal, por ejemplo, pueden ser considerables de acuerdo a Chinchilla (2009), incluso llegando a afectar la aplicabilidad de algunas leyes, en cuenta la recién aprobada Ley de Tránsito. 
La conformación de la Asamblea registró algunos cambios debido a la salida de cuatro diputadas, pero ello no alteró de manera significativa los balances partidarios ni las dinámicas de acuerdos reflejadas durante el período. Tres de las renuncias se debieron a que las titulares del cargo pasaran a formar parte del gabinete del gobierno: la diputada Del Vecchio para convertirse en Ministra de Seguridad, la diputada Zomer para convertirse en Ministra de Vivienda, y la diputada Antillón para ocupar el nuevo cargo de Ministra de Comunicación. La cuarta renuncia se dio por motivos de índole personal. La transferencia de éstas diputadas al Ejecutivo revela dos factores relevantes. ${ }^{21}$ Primero, la anuencia de sumarse al gabinete sugiere un alto grado de lealtad entre una parte de la bancada del PLN y el Ejecutivo, no siempre habitual, especialmente en el contexto en que se dieron algunas de las renuncias. Segundo, la necesidad de acudir a sus diputadas para llenar vacantes del gabinete sugiere la ausencia de cuadros políticos, más allá de su propia bancada, sobre los que pudiera recaer el partido.

Estos cambios no alteraron el balance de fuerzas en el Congreso dado que las diputadas en cuestión todas pertenecían al Partido Liberación Nacional y fueron sustituidas por militantes de esa misma agrupación, salvo en el caso de la ministra Antillón, quien ocupará su nuevo cargo concurrentemente con el de diputada. No obstante, una de las diputadas tuvo un substituto de distinto género, lo que implicó una disminución, aunque leve, de la representación femenina en el Congreso. Pese a ello, Costa Rica sigue manteniendo uno de los niveles más altos de representación femenina en el parlamento a nivel latinoamericano (Htun 2008).

Cuadro 5: Costa Rica, Distribución de Escaños en Asamblea Legislativa, 2008

\begin{tabular}{|c|c|c|c|c|c|c|}
\hline \multirow{3}{*}{ Partido } & \multicolumn{6}{|c|}{ Escaños } \\
\hline & \multicolumn{2}{|c|}{ Totales } & \multicolumn{2}{|c|}{ Hombres } & \multicolumn{2}{|c|}{ Mujeres } \\
\hline & $\#$ & $\%$ & $\#$ & $\%$ & $\#$ & $\%$ \\
\hline Liberación Nacional & 25 & $44 \%$ & 15 & $41 \%$ & 10 & $50 \%$ \\
\hline Acción Ciudadana & 16 & $28 \%$ & 10 & $27 \%$ & 63 & $0 \%$ \\
\hline Movimiento Libertario & 5 & $9 \%$ & 5 & $14 \%$ & 0 & $0 \%$ \\
\hline Unidad Social Cristiana & 5 & $9 \%$ & 3 & $8 \%$ & 2 & $10 \%$ \\
\hline Independientes & 3 & $5 \%$ & 1 & $3 \%$ & 2 & $10 \%$ \\
\hline Restauración Nacional & 1 & $2 \%$ & 1 & $3 \%$ & 0 & $0 \%$ \\
\hline Accesibilidad sin Exclusión & 1 & $2 \%$ & 1 & $3 \%$ & 0 & $0 \%$ \\
\hline Frente Amplio & 1 & $2 \%$ & 1 & $3 \%$ & 0 & $0 \%$ \\
\hline \multirow{2}{*}{ Totales } & 57 & $100 \%$ & 37 & $100 \%$ & 20 & $100 \%$ \\
\hline & & $100 \%$ & & $65 \%$ & & $35 \%$ \\
\hline
\end{tabular}

Fuente: Elaboración propia con datos de la Asamblea Legislativa. 
La designación del directorio legislativo en el 2008 tuvo como peculiaridad la reelección del presidente, Francisco Antonio Pacheco, por tercer período consecutivo. Esta es tan sólo la quinta ocasión en que ello ocurre en los últimos sesenta años, pero la primera en que coincide con la vacancia de las dos vicepresidencias de la República. El primer vicepresidente renunció a su cargo en el 2007 por la controversia creada alrededor de un memorándum que escribió conjuntamente con un diputado oficialista (el memo CasasSánchez). Dicho memo recomendaba al gobierno el uso del miedo y otras tácticas políticas cuestionables para el desarrollo de su campaña a favor de la ratificación del CAFTA. El repudio generalizado del documento forzó la salida del vicepresidente, colaborador cercano del presidente Arias y pieza clave del gabinete (Vargas Cullel 2008). La segunda vicepresidenta, como se ha visto, renunció en el 2008 como consecuencia del prematuro inicio de la campaña presidencial del 2010. La Constitución establece (artículo 135) que cuando ninguno de los vicepresidentes pueda llenar las faltas temporales o definitivas del Presidente, ocupará el cargo el Presidente de la Asamblea Legislativa. Pero no establece un procedimiento para la sustitución de las vicepresidencias. En las condiciones actuales esta situación adquiere especial significancia política, por dos factores.

Primero, por primera vez se crea, de manera concreta, la posibilidad de que la sucesión presidencial recaiga sobre una persona no electa directamente para el cargo, en vista de no haber vicepresidencias en ejercicio. El presidente de la Asamblea es elegido internamente por los y las diputadas y no por votación popular. Quien llegara a la Presidencia de la República en virtud de ocupar la presidencia de la Asamblea lo haría por la vía indirecta. Segundo, y tal vez más importante, se crea una situación de potencial incertidumbre para la que no existe procedimiento constitucional ni precedente jurídico en el país. Ausentes los vicepresidentes, la Constitución asigna la sucesión sobre el cargo de presidente de la Asamblea, no la persona. Como dicho cargo se renueva de forma anual ¿debe el país tener un nuevo presidente por cada año remanente del período presidencial ${ }^{22}$ Esta ambigüedad de las reglas crea el riesgo de disputas o cuestionamientos de legitimidad que podrían generar inestabilidad al régimen político.

\section{RELACIÓN ENTRE PODERES}

Las características del sistema político costarricense y su efecto sobre las relaciones entre poderes han sido descritas en versiones anteriores de este anuario (Vargas Cullel 2008, 2007). A modo de síntesis, el régimen combina un Ejecutivo relativamente débil con un Parlamento debilitado por la fragmentación del sistema partidario. La irresolución de estos poderes repercute en un balance de poderes favorable al Poder Judicial, ya que algunos conflictos políticos importantes no se resuelven políticamente sino en los tribunales y, en particular, en los de la jurisdicción constitucional. Dicha jurisdicción goza de amplios poderes, incluyendo la prerrogativa de resolver los conflictos de competencia entre poderes y demás entidades del Estado, y la potestad de pronunciarse, prospectivamente, respecto a la constitucionalidad de los proyectos de ley tramitados por 
el Congreso. ${ }^{23}$ En lo cotidiano, la Sala Constitucional ha dado una amplia interpretación a su papel como garante de derechos, otorgando poderes de veto a cualquier actor frente a cualquier acto público, si su apelación a la autoridad constitucional es aceptada. ${ }^{24}$ Adicionalmente, el Estado costarricense cuenta con múltiples mecanismos de control horizontal (la Contraloría General de la República, la Defensoría de los Habitantes, auditorías internas y otros) que vigilan y regulan la actividad del Ejecutivo y de sus entes administrativos, en ciertos casos mediante el ejercicio de controles a priori. Esto añade al veto constitucional otro administrativo, creando fuertes desincentivos para la cooperación entre actores políticos e institucionales.

La forma en que las características normativas del sistema afectan los incentivos de los actores es compleja, pero pueden resaltarse dos de sus facetas más importantes (Vargas Cullel 2005). ${ }^{25}$ En primer término, el activismo de las entidades de control horizontal y constitucional las ha fortalecido, junto a la ciudadanía en nombre de la cual actúan, con respecto al Ejecutivo y al Legislativo. Los actores individuales ya no requieren exclusivamente de los intermediarios políticos para impulsar sus intereses, pues pueden acudir directamente ante los órganos de control. Segundo, diversas acciones de la Sala Constitucional cercenaron los poderes informales de los que tradicionalmente había dispuesto el Ejecutivo para compensar su relativa debilidad. ${ }^{26}$ Si bien acertadas desde la perspectiva de las normas legales, estas acciones redujeron la capacidad decisiva del sistema. Ante la ausencia de competencias para actuar rápidamente en condiciones de alta prioridad otra vez se debilitaron los foros políticos con respecto a los jurídicos y administrativos con capacidad de modificar las acciones del Ejecutivo y del Legislativo.

En lo institucional, el Estado costarricense ha desarrollado una hipertrofia que limita severamente su capacidad de acción (Alfaro R. 2004; Programa Estado de la Nación 2004). El sector público está compuesto por más de 300 entidades (Ministerio de Planificación y Política Económica 2007a). ${ }^{27}$ Sus 19 ministerios se subdividen en 80 órganos adscritos con importantes grados de autonomía financiera y administrativa. La proliferación de organismos de diversa índole funcional y jurídica ha resultado en una estructura

23 La consulta de constitucionalidad desde la Asamblea puede ser obligada o facultativa. Ante esa la Sala resuelve sobre la constitucionalidad del trámite legislativo y señala "posibles" inconstitucionalidades sobre el fondo, pero esto último no es vinculante. Sólo lo sería si se acepta una acción de inconstitucionalidad una vez promulgada la ley. Agradezco a Constantino Urcuyo esta aclaración.

24 La Sala Constitucional interviene regularmente en el ámbito cotidiano, incluyendo en aspectos de índole técnico que son competencia de las entidades administrativas del Estado, por ejemplo, para ordenar procedimientos y tratamientos médicos, cuestionar estudios de impacto ambiental, definir la prioridad en el pago de pensiones, disponer sobre el suministro de servicios públicos, y pesar sobre decisiones administrativas de escuelas y colegios, entre muchos otros. Véase Hernández 2009.

25 Para un tratamiento completo del tema véase el artículo de Vargas Cullel (2005) de donde proceden las ideas expuestas en el presente párrafo.

26 Estos incluían, entre otros, el pasaje de legislación ordinaria mediante el uso del presupuesto, que por mandato constitucional debe aprobarse en un lapso de 90 días, y el uso del decreto ejecutivo para reglamentar, y así reinterpretar, la legislación aprobada por la Asamblea Legislativa.

$27 \quad$ El conteo institucional presentado en esta publicación excluye un conjunto de más de cincuenta instituciones identificadas por el Programa Estado de la Nación pero excluidas por el gobierno de su clasificación oficial. Para una descripción de dichas instituciones véase la página 34 del informe citado. 
Cuadro 6: Costa Rica, Instituciones del Sector Público Según Naturaleza Jurídica

\begin{tabular}{lc}
\hline Clasificación & Cantidad \\
\hline Poderes de la República & 3 \\
Tribunal Supremo de Elecciones & 2 \\
Poder Legislativo & 2 \\
Ministerio & 19 \\
Órganos adscritos a Ministerios & 80 \\
Instituciones autónomas & 33 \\
Órganos adscritos a instituciones autónomas & 11 \\
Instituciones semiautónomas & 11 \\
Órganos adscritos a instituciones semiautónomas & 1 \\
Empresas públicas & 22 \\
Entes públicos no estatales & 45 \\
Municipalidades & 81 \\
Consejos Municipales de Distrito & 8 \\
Empresas Municipales & 1 \\
Total & 319
\end{tabular}

Fuente: Dirección de Modernización del Estado y Programa Estado de la Nación.

altamente disfuncional. Dichos organismos se manejan de forma relativamente autónoma y concentran la mayor parte del presupuesto público. Por ejemplo, el presupuesto del sector descentralizado de instituciones autónomas, aprobado por la Contraloría General de la República, es independiente de los poderes Ejecutivo y Legislativo. Su importe representa poco más de dos terceras partes del gasto público y un 56\% de la contribución al PIB del gasto público (Vargas Cullel 2007). ${ }^{28}$

Todo ello significa que la gestión del gobierno, para ser efectiva, debe crear espacios de diálogo y negociación con la oposición, cosa que no parece haber sucedido durante el presente período. La coyuntura política del país en el 2008 se vio marcada por la incapacidad del Ejecutivo para desarrollar una relación política constructiva y fluida con la oposición, particularmente con la principal fuerza de oposición en el Congreso, el PAC. Dicha relación era absolutamente indispensable dado el estrecho triunfo del gobierno en las elecciones nacionales del 2006. ${ }^{29}$ En su lugar, como se ha descrito en secciones anteriores, el gobierno asumió un estilo poco conciliador y opaco en la toma de decisiones, reaccionando con resentimiento ante las críticas. ${ }^{30}$ Pese a carecer de un

28 Para mayor detalle del peso relativo presupuestario de las instituciones públicas costarricenses consúltese el organigrama elaborado por el Ministerio de Planificación disponible en http:/ / www.mideplan.go.cr/images / stories/mideplan/modernizacion/organigramas/Instituciones_segun_presup.pdf

29 El Presidente Arias obtuvo un 40,9\% de los votos frente a 39,8\% de su contendiente, Otón Solís, un margen de ganancia de 1,1 punto porcentuales, lo que equivalió a poco más de 18 mil votos.

30 Véase, por ejemplo, "Arias dices estar "harto" de trabas al Nacional”. La Nación, 8 de octubre, 2008; “Gobierno mintió al país sobre venta de bonos a China". La Nación, 11 de septiembre, 2008; “Oscar Arias: “Inteligencia de Taipei nos pilló en la mentira""'. La Nación, 13 de septiembre, 2008. 
mandato mayoritario y contundente el gobierno actuó como si lo tuviera, favoreciendo las vías de conveniencia y oportunidad en aras de impulsar sus decisiones.

Ante esta situación, y dado el predominio de la agenda complementaria al TLC en la gestión parlamentaria, no es sorprendente que, al igual que durante el 2007, en el 2008 no se dieran intentos por reformar la estructura del Estado. El propio gobierno, que declaró la modernización del Estado como una de las metas esenciales de su Plan Nacional de Desarrollo optó por dar preferencia a las medidas de reforma que pudieran ser adoptadas por el Poder Ejecutivo sin el concurso de otros poderes del Estado, dejando las reformas de leyes para una etapa ulterior. Dicha modernización, empero, requerirá de un rebalanceo de las relaciones entre poderes que incluya los mecanismos necesarios para la agilización de la toma de decisiones en el Ejecutivo tanto como en el Legislativo y el redimensionamiento de las atribuciones de la Sala Constitucional.

El Ejecutivo dio algunos pasos tentativos por reconocer la fuerza política y el liderazgo de la oposición, lo que habría sido un paso fundamental para la reconstitución de una relación partidaria constructiva. Aceptó, por ejemplo, la mediación de terceros para establecer un diálogo. Pero en última instancia abandonó esos esfuerzos. La oposición, por su parte, enfrascada en la Agenda Complementaria del TLC, no fue capaz de articular un plan distinto al del gobierno, y no logró constituirse en una verdadera alternativa política. La falta de un liderazgo efectivo tanto en el oficialismo como en la oposición retrasó la necesaria redefinición del sistema partidario, más bien debilitándolo.

Otro hecho notable durante el 2008 fue el inicio de juicios a los ex presidentes Calderón Fournier y Rodríguez Echeverría. Ambos mandatarios enfrentan cargos por presuntos hechos de corrupción revelados en el 2004. Los juicios, a diferencia de los procedimientos preliminares en el momento del escándalo, se han llevado a cabo sin espectacularidad. Su conducción es una importante prueba del imperio de la ley que reafirma el derecho al debido proceso mientras demuestra que ni los más altos dignatarios están por encima de la ley.

\section{RELACIÓN ENTRE NIVELES DE GOBIERNO}

Costa Rica tiene un sistema político unitario con bajos niveles de descentralización administrativa (Proyecto Estado de la Nación 2001). El nivel local de gobierno lo constituyen 81 municipalidades (Cuadro 6) cuya autoridad ejecutiva recae en los alcaldes o alcaldesas. La función deliberativa y la aprobación de políticas municipales recaen en los Concejos Municipales, constituidos por los y las regidoras municipales. Existen además los Síndicos y Síndicas municipales que actúan como representantes de distritos ante las municipalidades, con voz pero sin voto en los Concejos. Finalmente, los Concejos Municipales de Distrito son instancias de gobierno local en comunidades distantes de la cabecera del cantón en donde se asienta la municipalidad a la que pertenecen. Constituyen el nivel máximo de descentralización de la administración local y cuentan con sus propios ejecutivos (los intendentes) y concejales. Desde el año 
2002 todos los representantes en gobiernos locales son elegidos mediante votación popular. $^{31}$

El papel de las municipalidades dentro del Estado costarricense es bastante marginal (Vargas 2007). Su responsabilidad se limita a la prestación de servicios como el alumbrado eléctrico y la recolección de basura. La mayoría de los servicios públicos proviene de las instituciones autónomas o instituciones descentralizadas del gobierno central. Los impuestos municipales, al igual que las tasas de servicios municipales, son aprobados por el Poder Legislativo, y los presupuestos de las municipalidades son aprobados por la Contraloría General de la República. En el 2007 los impuestos municipales representaron un 3,3\% del PIB (Programa Estado de la Nación 2007). ${ }^{32}$ Si bien una reforma constitucional al artículo 170 en el 2002 creó la obligación de trasladar el 10\% de los ingresos del gobierno central a las municipalidades, supeditó su pago al correspondiente traslado de competencias a los gobiernos locales. Dicho traslado corresponde a la Asamblea Legislativa y se encuentra aún pendiente, por lo que la reforma no ha entrado en vigencia. La participación ciudadana en los gobiernos locales es restringida y los gobiernos locales no la promueven (Proyecto Estado de la Nación 2001). La elección de los dirigentes municipales no ha despertado el interés de los votantes: tan solo un $24 \%$ del electorado participó en la última elección de alcaldes celebrada en el 2006 (Alfaro 2007). Todo esto refleja la poca importancia del sector municipal en Costa Rica y la marcada resistencia que existe en el país a la transferencia de competencias a las municipalidades (Vargas 2007).

\section{FUNCIONAMIENTO Y CALIDAD DE LA DEMOCRACIA}

A pesar de ser una democracia consolidada con un alto grado de desarrollo humano, Costa Rica ha experimentado algunos síntomas de flaqueza en el funcionamiento y la calidad de su democracia. Su principal expresión ha sido la debilitación de la estructura partidaria y el creciente desencanto de la ciudadanía con la política, manifestada en su repudio de los partidos y los políticos tradicionales y en niveles ascendentes de abstención electoral (Programa Estado de la Nación 2008). Existe una desalineación entre los electores y sus representantes políticos que en parte procede de un sistema electoral y de partidos que es poco eficaz en asignar responsabilidades. Otra dimensión de debilidad ha sido la reciente tendencia al alza de la desigualdad y el deterioro de los servicios públicos que amenazan con aumentar la exclusión social.

La compleja estructura del sector público costarricense dificulta la toma de decisiones tanto por su densidad como por la necesidad de establecer controles en resguardo de la corrupción y el abuso. La confianza pública en el sistema ha sido minada por abusos pasados, lo que obliga a un control aún más receloso, que dificulta la capacidad de

Para una descripción completa del régimen municipal véase Alfaro (2007).

Vargas Cullel (2007) reporta una carga tributaria municipal significativamente inferior para el período 19952005. La discrepancia se debe a la reexpresión de la serie con un nuevo año base para el índice de precios en el año 2006. 
acción institucional. La desconfianza también se extiende a los partidos políticos y sus líderes, a quienes se culpa del dispendio de la hacienda pública y de los problemas sociales persistentes. La debilidad, fragmentación y desorganización de esos actores, al dificultar los acuerdos, hacen poco por reinstaurar la credibilidad y la confianza. Su propia desalineación con la sociedad a la que supuestamente representan empuja a los grupos sociales a buscar medios alternos para la expresión política.

En su expresión más positiva, esto lleva al desarrollo de movimientos sociales, al robustecimiento de la sociedad civil y, adonde existen los canales institucionales adecuados, al fortalecimiento de la democracia directa. El referéndum de ratificación del CAFTA constituye un ejemplo de cómo la participación directa de la ciudadanía puede romper el impasse de la política, a través de la movilización de la sociedad (Vargas Cullel 2009). No obstante, cuando la resolución de conflictos se sale del ámbito institucional y deja de estar constreñida por un conjunto de reglas, queda abierta a la manipulación oportunista de "outsiders" que pueden terminar minando las instituciones democráticas (Mayorga 2006). La probabilidad de que esto ocurra es mayor cuando, por haber perdido la confianza en los partidos tradicionales, el electorado se vuelve especialmente receptivo a otorgar poderes extraordinarios a líderes fuertes y carismáticos (Seligson 2008). El resultado puede ser una democracia "de la calle" irrespetuosa del debido proceso, los derechos de las minorías y el imperio de la ley.

A pesar de que Costa Rica por el momento ha sorteado estas presiones de forma exitosa, su incapacidad para reformar la estructura institucional del régimen político ha sido una importante fuente de debilidad. La profundización de su calidad democrática requiere, por un lado, tanto de la expansión de la participación como del refuerzo de los mecanismos de representación y, por el otro, de un aparato estatal efectivo e incluyente, capaz de asegurar el avance sostenido del bienestar común (Abente Brun 2008). Todo esto pasa por un conjunto de reformas que el país ha venido postergando. Como mínimo, para evitar el deterioro del funcionamiento y la calidad democrática debe mejorarse la capacidad de los partidos políticos para superar el bloqueo institucional, reconstruirse la legitimidad de la representación política y corregirse las debilidades conocidas del sistema electoral. 
Apéndice: Costa Rica, Leyes aprobadas y su duración, enero-diciembre 2008

\begin{tabular}{lccccr}
\hline \multirow{2}{*}{\multicolumn{1}{c}{ Tipo de Ley }} & \multicolumn{5}{c}{ Número de Días } \\
\cline { 2 - 6 } & Promedio & Mínimo & Máximo & St. Dev & Leyes \\
\hline Agenda Complementaria TLC (AC) & 502.55 & 18 & 909 & 341.14 & 11 \\
Autorizaciones locales & 826.37 & 379 & 2204 & 417.92 & 20 \\
Convenios internacionales & 780.91 & 88 & 1823 & 546.17 & 11 \\
Declaraciones y Benemeritazgos & 699.33 & 535 & 976 & 241.01 & 3 \\
Legislación ordinaria sustantiva & 880.31 & 141 & 2287 & 541.89 & 28 \\
Presupuesto & 60.75 & 29 & 92 & 25.73 & 5 \\
Total & 743.89 & 18 & 2287 & 495.06 & 78 \\
\hline
\end{tabular}

Fuente: elaboración propia con datos de la Asamblea Legislativa.

Costa Rica, Leyes aprobadas por iniciativa y duración, enero-diciembre 2008

\begin{tabular}{lccccc}
\hline \multirow{2}{*}{ Iniciativa } & \multicolumn{5}{c}{ Número de Días } \\
\cline { 2 - 6 } & Promedio & Mínimo & Máximo & St. Dev & Leyes \\
\hline Ejecutivo & 606.71 & 18 & 1823 & 478.04 & 32 \\
Legislativo & 842.79 & 141 & 2287 & 488.73 & 46 \\
Total & 743.89 & 18 & 2287 & 495.06 & 78 \\
\hline
\end{tabular}

Fuente: elaboración propia con datos de la Asamblea Legislativa.

Costa Rica, Leyes aprobadas por iniciativa y duración, período legislativo

\begin{tabular}{lccccc}
\hline Iniciativa & 2004 & 2005 & 2006 & 2007 & Promedio \\
\hline Ejecutivo & 385 & 661 & 873 & 548 & 617 \\
Legislativo & 640 & 708 & 723 & 553 & 656 \\
Promedio & 513 & 685 & 798 & 551 & 636 \\
\hline
\end{tabular}

Fuente: Programa Estado de la Nación 2008. 


\section{REFERENCIAS}

Abente Brun, Diego. 2008. "Introduction". In Latin America's Struggle for Democracy, edited by L. J. Diamond, M. F. Plattner and D. Abente Brun. Baltimore, Md.: Johns Hopkins University Press.

Achard, Diego, y Luis E. González. 2005. A Challenge for Democracy: Political Parties in Central America, Panama and the Dominican Republic. Washington, D.C.: Inter-American Development Bank, International Institute for Democracy and Electoral Assistance, Organization of American States, and United Nations Development Program.

Alfaro R., Ronald. 2004. "Instituciones Estatales en Costa Rica: Un Balance del Período 1990-2003". San José, Costa Rica: Programa Estado de la Nación en Desarrollo Humano Sostenible. 2007. "Elecciones de Alcaldes Municipales en Costa Rica 2006". Centro de Investigación y Estudios Políticos, Universidad de Costa Rica. [En línea] <http: / / www.estudiospoliticos.ucr.ac.cr/ articulos2007.php>. [Consulta: Abril 2009].

Boidi, María Fernanda. 2008. "“Throw them All Out"? Attitudes towards Political Parties in the Americas". In Challenges to Democracy in Latin America and the Caribbean: Evidence from the Americas Barometer 2006-2007, edited by M. A. Seligson. Nashville: Latin American Public Opinion Project.

CEPAL. 2008. Balance preliminar de las economías de América Latina y el Caribe. Santiago: Naciones Unidas. Chinchilla, Rosaura. 2009. "La primera responsabilidad en el acto de legislar". La Nación, 11 de enero.

Chong, Alberto, and Juan Benavides. 2007. "Privatization and Regulation in Latin America". In The state of State Reform in Latin America, edited by E. Lora. Stanford, CA.: Stanford University Press.

CID-Gallup. 2008. "Encuesta para el diario La República, noviembre 2008". [En línea] <http://www. larepublica.net>. [Consulta: enero 2009].

Comisión de Notables. 2005. "Informe Final de Carácter General no Vinculante al Presidente de la República sobre el Tratado de Libre Comercio entre Centroamérica, República Dominicana y Estados Unidos de América". San José, Costa Rica.

Contraloría General de la República. 2008a. "Informe sobre el cumplimiento de las metas establecidas en los contratos con la ciudadanía en el Plan Nacional de Desarrollo 2006-2010 correspondiente al Sector Educación". San José: Contraloría General de la República.

2008b. "Informe sobre el cumplimiento de las metas establecidas en los contratos con la ciudadanía en el Plan Nacional de Desarrollo correspondiente al Sector Salud". San José: Contraloría General de la República.

Hernández, Rubén. 2009. “¿Quién gobierna en Costa Rica?” La Nación, 17 de marzo.

Htun, Mala. 2008. "Political Inclusion and Social Inequality: Women, Afro-descendants, and Indigenous Peoples". In Constructing Democratic Governance in Latin America, edited by. J. I. Domínguez and M. Shifter. Baltimore: Johns Hopkins University Press.

INEC y PNUD. 2008. "Resultados Módulo Sobre Victimización: Encuesta de Hogares de Propósitos Múltiples Julio 2008". San José: Instituto Nacional de Estadística y Censo y Programa Naciones Unidades Para el Desarrollo.

Lora, Eduardo. 2007. "Trends and Outcomes of Tax Reform". In The State of State Reform in Latin America, edited by. E. Lora. Stanford, CA.: Stanford University Press.

Mayorga, René Antonio. 2006. "Outsiders and Neopopulism: The Road to Plebiscitary Democracy." In The Crisis of Democratic Representation in the Andes, edited by S. Mainwaring, A. M. Bejarano and E. Pizarro Leongómez. Stanford, Calif.: Stanford University Press.

Ministerio de Planificación y Política Económica. 2007a. "Manual Explicativo de los Organigramas del Sector Público Costarricense". San José: MIDEPLAN, Universidad de Costa Rica y Programa Estado de la Nación.

2007b. “Plan Nacional de Desarrollo ‘Jorge Manuel Dengo Obregón' 2006-2010". [En línea] <http://www.mideplan.go.cr/content/view/69/371/> [Consulta: Febrero 2009].

2009. “Informe de Evaluación del Plan Nacional de Desarrollo 2008”. Ministerio de Planificación Nacional y Política Económica. 
Programa Estado de la Nación. 2004. Décimo Informe Estado de la Nación en Desarrollo Humano Sostenible. San José, Costa Rica: Programa Estado de la Nación.

2008. Décimocuarto Informe Estado de la Nación en Desarrollo Humano Sostenible. San José, Costa Rica: Programa Estado de la Nación.

Proyecto Estado de la Nación. 2001 Auditoría Ciudadana Sobre la Calidad de la Democracia. San José, Costa Rica: Proyecto Estado de la Nación.

Ramírez H., Odir. 2008. "Caracterización Cuenca Río Sardinal". San José: Ministerio de Ambiente y Energía.

Seligson, Mitchell A. 2008. "The Rise of Populism and the Left: Challenge to Democratic Consolidation?" In Challenges to Democracy in Latin America and the Caribbean: Evidence from the Americas Barometer 2006-2007, ed. M. A. Seligson. Nashville: Latin American Public Opinion Project.

Tarrow, Sidney G. 1994. Power in Movement: Social Movements, Collective Action, and Politics. Cambridge England: Cambridge University Press.

UNIMER, RI. 2004. “Encuesta Para el Diario La Nación, diciembre 2004”. [En líneas] <http:/ / www.nacion. com/ln_ee/2004/diciembre/14/pais1.html\#234930> [Consulta: enero 2009].

2008. "Encuesta para el diario La Nación, septiembre 2008". [En línea] <http://www.nacion. com> [Consulta: enero 2009].

Vargas Cullel, Jorge. 2005. “Está el sistema político costarricense al borde del colapso?" Centro de Investigación y Adiestramiento Político Administrativo (CIAPA).

. 2007. "Costa Rica: Fin de una Era Política”. Revista de Ciencia Política Volumen Especial: 113-28.

. 2008. "Costa Rica: Una Decisión Estratégica en Tiempos Inciertos". Revista de Ciencia Política 28 (1):147-69.

2009. “El referéndum sobre el Tratado de Libre Comercio entre Estados Unidos, Centroamérica y República Dominicana". In Jornada de Análisis sobre el Tratado de Libre Comercio entre Estados Unidos, Centroamérica y República Dominicana, edited by L. Feoli, C. Urcuyo and C. Urcuyo. San José: CIAPA

Ludovico Feoli. Costarricense. Director del Centro de Investigación de Adiestramiento Político Administrativo (CIAPA) en San José, y el Center for Inter-American Policy and Research en la Universidad de Tulane, Nueva Orleans, adonde también es profesor investigador. Ph.D en Ciencias Políticas y MS en estudios latinoamericanos de la Universidad de Tulane, y Bachiller en Economía del Claremont McKenna College.

[E-mail: lfeoli@ciapa.org] 
